\title{
The Effects of Starvation on Crayfish Responses to Alarm Odor
}

\author{
Brian A. Hazlett \\ Department of Ecology and Evolutionary Biology, University of Michigan, \\ Ann Arbor, MI, USA
}

\begin{abstract}
The effect of starvation on responses to alarm odor was tested with individuals of an invasive and a native species of crayfish. I predicted that chemical predator cues would inhibit feeding less in starving than well-fed animals, and that this decrease would be stronger in a native compared with an invasive species. Individuals were exposed to food odor and then alarm odor after 3 and $10 \mathrm{~d}$ of starvation. The inhibition of food-related behavior patterns was similar on the $2 \mathrm{~d}$ of testing for individuals of the invasive species, Orconectes rusticus. Individuals of $O$. virilis showed a significant reduction in the effects of alarm odor detection on day 10 compared with day 3 of starvation. The lack of a change in responses to alarm odors between days of testing by individuals of $O$. rusticus may be because they are more responsive to alarm odors than individuals of $O$. virilis. This behavioral difference could contribute to the successful range extension of $O$. rusticus.
\end{abstract}

Corresponding author: Brian A. Hazlett, Department of Ecology and Evolutionary Biology, University of Michigan, Ann Arbor, MI 48109, USA. E-mail: bhazlett@umich.edu

\section{Introduction}

All animals face trade-offs in their activities as they receive multiple pieces of information and have multiple motivational levels that modify their behavioral responses. One of the most common trade-offs animals experience is between foraging activities and the risk of predation (Werner \& Anholt 1993; Skalski \& Gilliam 2002). In most species, foraging activities increase the risk of predation (Wisenden et al. 1999), so choices regarding the levels of foraging activities must be made utilizing cues about the risk of predation. Similarly, with a given level of predation risk as indicated by the cues animals receive, one would predict greater risk taking as food motivation increases.

While many studies have focused on the existence of the ecological trade-off between foraging and predation risk (see review by Lima 1998), fewer have 
examined the behavioral mechanisms mediating the solution to the conflict. Anholt et al. (2000) measured the activity levels of anuran tadpoles under combinations of levels of food availability and predation risk cues. They found the same relative magnitude of predation cue effects at all food levels, indicating no shifts in the nature of the interaction of the two inputs.

Many animals initially respond to a cue associated with elevated predation risk, such as predator odor, with an almost complete cessation of feeding activities for a period of time following detection of the predation-risk cue (the hierarchical model of the structure of behavior) (Hazlett 1999). Crayfish, in contrast, usually show a significant reduction in feeding activity in the presence of cues such as predator odor, but do not completely stop feeding (the alternation model) (Hazlett 1999). They apparently can afford to keep feeding in the face of danger, as indicated by a chemical cue, because the tail flip, a behavior elicited by tactile stimuli, offers an alternative to ceasing motion (Hazlett 1999; Bouwma \& Hazlett 2001).

Invasive species show a number of behavioral differences compared with native species they may displace. Invasive crayfish species are reported to be more aggressive (Capelli \& Munjal 1982), use a broader range of information about predation risk (Hazlett 2000; Hazlett et al., in press), and remember learned associations longer (Hazlett et al. 2002). Yet, effects of predators on the foraging behavior of native and invasive species have not been compared. As individuals spreading to new habitats will more frequently encounter predators novel to them, we can predict that individuals of those species will both (a) learn to associate novel cues with unlearned predation risk cues (i.e. alarm odors) (Hazlett et al. 2002) and (b) rely upon alarm cues more strongly than native species. If species have evolved in areas of particularly high and diverse predation pressure, individuals should be more sensitive to predation-risk cues. The latter prediction would suggest that individuals of species that are successful invaders change in their responses to predation-risk cues less as food motivation increases.

In this study, I examined the effects of starvation on the suppression of feeding responses by crayfish upon reception of cues indicating elevated predation. I predicted that starvation would decrease the level of inhibition of feeding by a predator cue and that this decrease would be stronger in a native compared with an invasive species.

\section{Materials and Methods}

The two species studied were the native Midwest cambarid Orconectes virilis and the invasive species Orconectes rusticus that has spread through much of the Midwest since introduction from southern Ohio River drainage systems. Individuals of the two species were collected from Burt Lake, Cheboygan county, in the northern lower peninsula of Michigan. The two species have coexisted in Burt Lake for at least $25 \mathrm{yr}$ with little change in their relative abundances (Hazlett, pers. obs.). They were tested in the laboratory at the University of Michigan Biological Station during July and August, 2002. Individuals used were between 35 and $40 \mathrm{~mm}$ cephalothorax length for both species. 
Crayfish were held in communal aquaria and fed cod fish for several days to make sure they recognized the fish odor as food (Hazlett 1994). They were then placed in visually isolated, individual 371 aquaria with 151 of Douglas Lake water, constant aeration, and half of a clay pot for shelter. Three days later they were tested with a sequence of three conditions: addition of $10 \mathrm{ml}$ of control water, then after $2 \mathrm{~min} 10 \mathrm{ml}$ of food odor (see below) was added, followed after $2 \mathrm{~min}$ by the addition of $10 \mathrm{ml}$ of conspecific alarm odor. All solutions were introduced with a syringe. The crayfish were left in the observation aquaria for an additional $7 \mathrm{~d}$ and tested again after a total of $10 \mathrm{~d}$ without food. Fifteen individuals of each species were tested, once after $3 \mathrm{~d}$ starvation and once after $10 \mathrm{~d}$. Previous studies have shown that the alarm odors decay and are ineffective after about $6 \mathrm{~h}$ (Hazlett 1999) and food odors decay after $24 \mathrm{~h}$ (Hazlett et al., in press). Thus, by day 10 there should be no cues left from the introductions on day 3.

Behavior patterns were recorded for 2 min following each addition. They included feeding movements of the chelipeds and walking legs, locomotion (movement of the whole crayfish as a result of walking leg activity), and posture (raised posture $=$ cephalothorax raised well off of the substrate and chelipeds held horizontally or higher; lowered posture $=$ chephalothorax lowered, in contact with the substrate, tips of chelipeds touching the substrate and the abdomen curled forward; or intermediate posture) (Hazlett 1999, 2000). The number of seconds spent executing each of the behaviors or in each posture was recorded. Tests with a sequence of odors (food + alarm) have been found to be more sensitive than tests with a single input (Bouwma \& Hazlett 2001).

The food odor was prepared by macerating $20 \mathrm{~g}$ of cod fish in $150 \mathrm{ml}$ of Douglas Lake water and filtering in coarse filter paper to remove particles. The alarm odor was prepared by macerating a medium-sized conspecific crayfish (25-30 mm carapace length) in $150 \mathrm{ml}$ of Douglas Lake water and filtering. These concentrations of odors have been used with both species in other studies, and are known to affect the behavior of these crayfish (Hazlett 1999; Hazlett et al. 2002).

Three behavior patterns were analyzed (feeding behavior, raised posture, and locomotion) as other studies of these species have indicated these behaviors are the most sensitive indicators of responses to food-related inputs. Time in the three postures were not independent, as the animals had to be in one of the three all of the time. Therefore, only the time in the raised posture was analyzed statistically. The other behavior patterns could occur alone or in any combination, and thus are independent measures. The number of seconds spent during the 2-min observation periods were extracted from the data and analyzed via a repeated measures ANOVA for each species. The main effect examined was treatment (food odor alone or alarm odor added). The statistic of interest is the interaction term that indicates whether there were differences in the responses to treatment by day.

\section{Results}

Introduction of food odor resulted in a strong increase in the amount of time individuals spent executing feeding behaviors, locomotory activities, and being in 
Table 1: Mean (SE) number of seconds spent by individuals of Orconectes rusticus and Orconectes virilis during 2-min observation periods in three behaviors (feeding, raised posture, and locomotion) under three conditions after 3 and $10 \mathrm{~d}$ without food

\begin{tabular}{|llll|}
\hline & Control water & Food odor & Alarm odor \\
\hline $\begin{array}{l}\text { Orconectes rusticus } \\
\text { Day 3 }\end{array}$ & & \\
$\quad$ Feeding & $0.0(0.0)$ & $42.5(10.5)$ & $1.9(0.6)$ \\
$\quad$ Raised & $0.0(0.0)$ & $18.5(6.7)$ & $0.4(0.4)$ \\
Locomotion & $0.3(0.3)$ & $30.0(9.5)$ & $2.8(0.7)$ \\
Day 10 & & & \\
Feeding & $0.1(0.1)$ & $48.0(11.9)$ & $8.0(3.8)$ \\
Raised & $0.0(0.0)$ & $27.0(9.3)$ & $5.4(3.7)$ \\
Locomotion & $0.6(0.3)$ & $39.9(12.3)$ & $7.9(2.9)$ \\
Orconectes virilis & & & \\
Day 3 & & $80.0(10.3)$ & $13.7(3.6)$ \\
Feeding & $0.3(0.2)$ & $60.6(10.1)$ & $11.2(3.9)$ \\
Raised & $0.0(0.0)$ & $60.5(9.6)$ & $15.5(2.4)$ \\
Locomotion & $0.4(0.2)$ & $72.3(7.3)$ & $43.4(10.3)$ \\
Day 10 & & $57.1(8.4)$ & $30.9(8.3)$ \\
Feeding & $0.0(0.0)$ & $64.0(7.8)$ & $45.2(8.8)$ \\
Raised & $0.0(0.0)$ & & \\
Locomotion & $0.2(0.2)$ & & \\
\hline
\end{tabular}

the raised posture. This result was true for individuals of both species and for both days tested (Table 1). When alarm odor was introduced, the time spent in those behaviors significantly decreased. For individuals of both species, treatment had significant effects (main effect $F$ values from ANOVAs associated with $p<0.001$ ) for feeding, raised posture and locomotion. This was true on both days crayfish were tested (Table 1).

As indicated by the interaction terms of the ANOVA tests, for individuals of Orconectes rusticus, there was no difference between the $2 \mathrm{~d}$ of testing $(\mathrm{F}=0.002$, $\mathrm{p}=0.965 ; \mathrm{F}=0.24, \mathrm{p}=0.628$; and $\mathrm{F}=0.56, \mathrm{p}=0.459$ for feeding, raised, and locomotion, respectively). Alarm odors decreased responses to food odor similarly on the two test days. For individuals of $O$. virilis, there was a significant interaction term for feeding $(\mathrm{F}=5.34, \mathrm{p}=0.028)$ and locomotion $(\mathrm{F}=4.8$, $\mathrm{p}=0.045)$, indicating that they responded differently to the addition of alarm odor on the $2 \mathrm{~d}$. The interaction term for the time spent in the raised posture by individuals of $O$. virilis was not significant $(\mathrm{F}=2.24, \mathrm{p}=0.145)$. The difference appears to be a reduction in the strength of inhibition of food responses by alarm odor introduction on day 10 (Table 1). Individuals of $O$. virilis responded to alarm odor less strongly when they had been without food longer.

\section{Discussion}

The reduction in food-related behavior patterns upon the detection of a cue indicating elevated predation risk seen in individuals of both species of crayfish is 
similar to that reported in other studies (Smith 1981; Vadas et al. 1994; Brown \& Smith 1996; Uiblein et al. 1996; Hazlett 1999; Chivers et al. 2000) and is to be expected (Werner \& Anholt 1993). As predicted, individuals of Orconectes virilis showed a pattern of reduced inhibition of feeding behaviors by alarm odor as motivation related to food increased. Ten days of starvation resulted in a shift in the balance between the responses shown to conflicting inputs (cues indicating foraging opportunity and avoiding predation). Earlier work on $O$. virilis (Hazlett et al. 1975) indicated that 7-10 d of starvation had the peak effect upon aggressive behavior in this species; longer periods without food caused a relative decline in effects upon aggression.

Individuals of Orconectes rusticus showed a trend towards a reduction of the effect of detection of alarm odor, but this was not significant. Rather, individuals of this species responded statistically similarly to detection of alarm odor and food odor on the $2 \mathrm{~d}$ of testing. This response could be mediated by individuals of this species being either more consistently responsive to conspecific alarm odor or by being less strongly influenced by increased levels of feeding motivation by the additional days without food. Glycogen reserves are strongly affected by $7 \mathrm{~d}$ of starvation in O. virilis (Hazlett et al. 1975) but comparable data for O. rusticus are not available. Whatever the mechanism underlying the pattern, the result is individuals of this (invasive) species maintain a higher level of vigilance when a cue indicating elevated predation risk is detected, compared with the native species, $O$. virilis.

Other comparisons of $O$. rusticus and native species of crayfish have shown behavioral differences that may contribute to the success of $O$. rusticus in expanding its range. Individuals of $O$. rusticus are more aggressive than those of O. virilis or O. propinquus (Capelli \& Munjal 1982). Individuals of O. rusticus respond to heterospecific alarm odors just as strongly as they do to conspecific alarm odors (Hazlett 2000) and they remember learned associations longer than do individuals of native species (Hazlett et al. 2002). In combination, the results of this and other studies suggest that individuals of $O$.rusticus are more responsive to alarm odor than are those species that have not recently expanded their ranges. Responding appropriately to cues indicating elevated predation risk has been shown to reduce the probability of predation in a number of species (Mathis \& Smith 1993; Wisenden et al. 1999; Downes 2002). Such an ability would be favored if the native habitat of the invasive species had a particularly harsh background of predation pressure. This evolved ability would be particularly important for potential prey animals encountering novel predators as they expand their range.

In conclusion, this study suggests an additional feature of the behavior of invasive species that, along with other features of their biology, may contribute to successful range extension.

\section{Acknowledgements}

I would like to thank the staff of the University of Michigan Biological Station for their assistance, Keith Pecor for help with collecting crayfish, and Keith Pecor and Catherine Bach for their comments on the manuscript. 


\section{Literature Cited}

Anholt, B. R., Werner, E. \& Skelly, D. K. 2000: Effect of food and predators on the activity of four larval ranid frogs. Ecology 81, 3509-3521.

Bouwma, P. \& Hazlett, B. A. 2001: Integration of multiple predator cues by the crayfish Orconectes propinquus. Anim. Behav. 61, 771-776.

Brown, G. E. \& Smith, R. J. F. 1996: Foraging trade-offs in fathead minnows (Pimephales promelas, Osteichthyes, Cyprinidae): acquired predator recognition in the absence of an alarm response. Ethology 102, 776-785.

Capelli, G. M. \& Munjal, B. L. 1982: Aggressive interactions and resource competition in relation to species displacement among crayfish of the genus Orconectes. J. Crustacean Biol. 2, 486-492.

Chivers D. P., Puttlitz, M. H. \& Blaustein, A. R. 2000: Chemical alarm signaling by reticulate sculpins, Cottus perplexus. Environ. Biol. Fish 57, 347-352.

Downes, S. J. 2002: Does responsiveness to predator scents affect lizard survivorship? Behav. Ecol. Sociobiol. 52, $38-42$.

Hazlett, B. A. 1994: Crayfish feeding responses to zebra mussels depend on microorganisms and learning. J. Chem. Ecol. 20, 1525-1535.

Hazlett, B. A. 1999: Responses to multiple chemical cues by the crayfish Orconectes virilis. Behaviour 136, $161-177$.

Hazlett, B. A. 2000: Information use by an invading species: do invaders respond more to alarm odors than native species? Biol. Invasions 2, 289-294.

Hazlett, B. A., Rubenstein, D. \& Rittschof, D. 1975: Starvation, energy reserves, and aggression in the crayfish Orconectes virilis (Hagen, 1870) (Decapoda, Cambaridae). Crustaceana 28, 11-16.

Hazlett, B. A., Acquistapace, P. \& Gherardi, F. 2002. Differences in memory capabilities in invasive and native crayfish. J. Crustacean Biol. 22, 439- 448.

Hazlett, B. A., Burba, A., Gherardi, R. \& Acquistapace, P. (in press): Invasive species use a broader range of predation-risk cues than native species. Biological Invasions.

Lima, S. L. 1998: Stress and decision making under the risk of predation: recent developments from behavioral, reproductive, and ecological perspectives. Adv. Study Behav. 27, 215-290.

Mathis, A. \& Smith, R. J. F. 1993: Chemical alarm signals increase the survival time of fathead minnows (Pimephales promelas) during encounters with northern pike (Esox lucius). Behav. Ecol. 4, $260-265$.

Skalski, G. T. \& Gilliam, J. F. 2002: Feeding under predation hazard: testing models of adaptive behavior with stream fish. Am. Nat. 160, 158-172.

Smith, R. J. F. 1981: Effect of food deprivation on the reaction of Iowa darters (Etheostoma exile) to skin extract. Can. J. Zool. 59, 558-560.

Uiblein, F., Roca, J. R. R., Baltana, A. \& Danielopol, D. L. 1996: Tradeoff between foraging and antipredator behaviour in a macrophyte dwelling ostracod. Arch. Hydrobiol. 137, 119-133.

Vadas, R. L. Sr, Burrows, M. T. \& Hughes, R. N. 1994: Foraging strategies of dogwelks, Nucella lapillus (L.): interacting effects of age, diet and chemical cues to the threat of predation. Oecologia 100, 439-450.

Werner, E. E. \& Anholt, B. 1993: Ecological consequences of the trade-off between growth and mortality rates mediated by foraging activity. Am. Nat. 142, 242-272.

Wisenden, B. D., Cline, A. \& Sparkes, T. C. 1999: Survival benefit to antipredator behavior in the amphipod Gammarus minus (Crustacea: Amphipoda) in response to injury-released chemical cues from conspecifics and heterospecifics. Ethology 105, 407-414.

Received: November 18, 2002

Initial acceptance: February 11, 2003

Final acceptance: April 7, 2003 (S.A. Foster) 